\title{
PTU-010 DOES NATIONAL BOWEL CANCER SCREENING PROGRAMME (NBCSP) AFFECT COLONOSCOPISTS' PERFORMANCE OVER TIME?
}

doi:10.1136/gut.2011.239301.138

T R Lim,* M Thian, C Grimley ${ }^{1}$ Department of Gastroenterology, East Lancashire Hospitals NHS Trust, Blackburn, UK

Introduction The South Lancashire Bowel Cancer Screening Programme (BCSP) went 'live' in June 2008. All colonoscopists enrolled in the BCSP are required to undergo a validated endoscopic accreditation process to become bowel cancer screeners. However, it is uncertain whether participation in the BCSP affects colonoscopists' performance over time.

Methods The performances of five bowel cancer screeners in the South Lancashire BCSP was analysed. 320 colonoscopies performed during month 1-6 were compared to 486 colonoscopies performed during month 13-18. Performances were scored using caecal intubation rates, duration of procedure, adenoma and cancer detection rates.

Results All screeners were accredited at the beginning of the BCSP. There was no difference in caecal intubation rate or polyp/ cancer detection rate amongst the colonoscopists over time. Caecal intubation rate was high in the first half of the audit period (96.24\%), as well as in the latter half of the audit period (95.45\%). Adenoma detection rate also remained above the national target (35\%) at $51.22 \%$ (month $1-6$ ) and $52.89 \%$ (month $13-18$ ).

Conclusion Bowel cancer screeners who underwent validated accreditation process continue to perform at a consistently high standard, above the national target over time. The high standard expected of a bowel cancer screener prior to joining the programme may explain the consistent performance shown in this audit.

Competing interests None.

Keywords bowel cancer screening, colonoscopy, performance. 